\title{
Towards an Agent-based Simulation of Building Stock Development for the City of Hamburg
}

\author{
Thomas Preisler, Tim Dethlefs, Wolfgang Renz \\ Faculty of Engineering and Computer Science, \\ Hamburg University of Applied Sciences, \\ Berliner Tor 7, 20099 Hamburg, Germany \\ \{thomas.preisler,tim.dethlefs,wolfgang.renz\}@haw-hamburg.de
}

\author{
Ivan Dochev, Hannes Seller, Irene Peters \\ Technical Urban Infrastructure Systems, \\ HafenCity University Hamburg, \\ Überseeallee 16, 20457 Hamburg, Germany \\ \{ivan.dochev,hannes.seller,irene.peters\}@hcu-hamburg.de
}

\begin{abstract}
In the context of European climate goals municipalities have an increasing interest in an accurate estimation of current and future energy demand in buildings, as the domestic energy consumption is one of the major adjusting screws for the reduction of electrical and thermal energy consumption, whereas the demand for space heating has the highest impact. As part of the ongoing GEWISS project it is planned to create a geographical information system (GIS) to visualize domestic and industrial heat consumption in the city of Hamburg (Germany) to support political decision making by linking the development of urban areas and the district heating grid. Additionally, it is planned to provide simulation capabilities to offer planning assistance for future development. This paper will present the underlying agent-based simulation system that is used to simulate the development of the building stock. Thereby, the simulation approach and first results regarding the development of the renovation state of the building stock based on a study about the renovation behavior of different types of home-owners of detached and terraced houses will be presented.
\end{abstract}

\section{INTRODUCTION}

I N THE context of European climate goals as well as the Energy Transition in Germany, municipalities have an increased interest in an accurate estimation of current and future energy demands in the building and traffic sector. The domestic energy consumption is one of the major parameter for the reduction of both electrical and thermal energy consumption, whereas the demand for space heating plays the biggest role [1]. Thus, profound knowledge about the building stock and its consumption is needed to tackle the challenge of energy transition towards non-fossil sources and their efficient integration into the energy mix. Future energy planning needs concepts like Smart Cities, a collective term for holistic development concepts that aim at constructing cities that are more efficient, technological advanced and environmentally sustainable [2]. This includes the knowledge of spatial distribution of energy consumption in an urban context.

For this purpose the ongoing GEWISS (Geographical Information and Simulation System for Urban Heat Flows, 2014-2018) project [3] $]^{1}$ creates a tool based on geographical information systems (GIS) to visualize domestic and industrial heat consumption in the city of Hamburg, Germany. The tool supports political decision making by linking the development

${ }^{1}$ German publication of urban areas and the district heating grid. The grid-based heat supply needs to be planned with respect to the existing as well as future building stock. Aspects such as the conversion of urban areas, redensification, redevelopment or demolition as well as renovation of buildings should be aligned to locally available heat sources. Therefore, it is necessary to collect and analyze the required data with respect to the spatial location in a GIS. The goal of the GEWISS project is to provide such a GIS with information about heat demand and supply as well as simulation capabilities to offer planning assistance for future development [4].

This paper will present the agent-based simulation system of the GEWISS project that is going to be used to simulate the development of the building stock in Hamburg. Currently, it focuses on the renovation behavior of different types of homeowners of detached and terraced houses. Thereby, it simulates how the renovation level of the buildings and depending on that their heat energy demand could develop from 2016 to 2050. Future versions of the simulation system will support other types of residential buildings like apartment houses as well as non-residential buildings like factories or administration buildings. Apart from the renovation of buildings their demolition and reconstruction as well as aspects like redensification are also planned to be supported by the simulation system. In order to simulate the renovation behavior of different types of detached and terraced house owners, a study about motivations, barriers and target groups for energetic building renovation in Germany [5] ${ }^{2}$ is taken as a basis to develop different types of home-owner agents implementing different renovation behavior. The agent-based simulation system is realized using Repast Simphony [6]. Figure 1 illustrates the types of buildings that are part of the current version of the simulation system (as these types are covered by the study from [5]) by showing a map extract from a residential area in the City of Hamburg where the building stock mainly consists of detached and terraced houses.

The remainder of this paper is structured as follows: The next section will give a brief overview about related work. Section III will describe the simulation approach before Section IV describes the developed simulation system in detail.

${ }^{2}$ German publication 


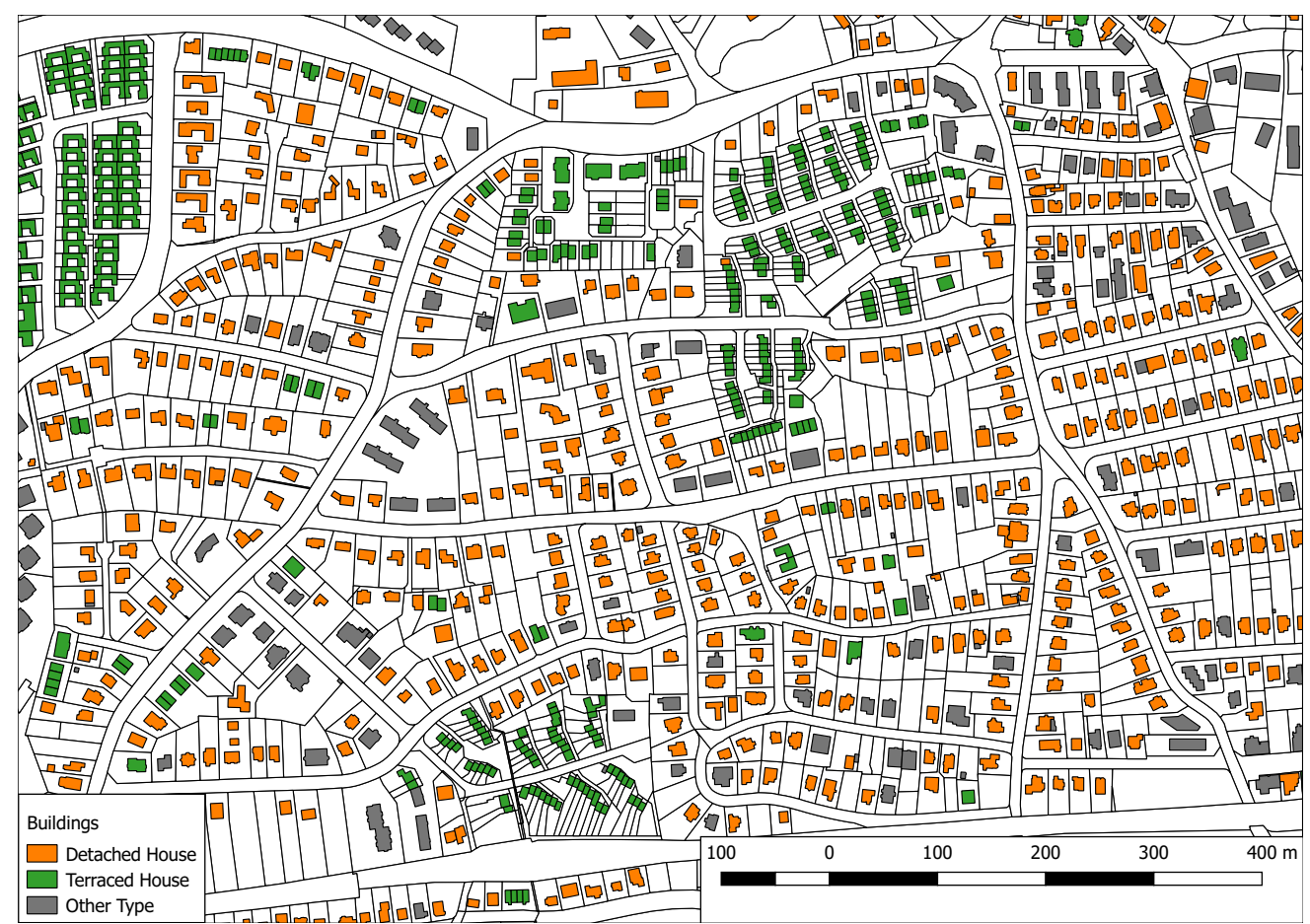

Fig. 1. Map extract from Hamburg showing a residential area with detached, terraced and apartment houses in the district of Othmarschen.

Afterwards, the simulation results are presented in Section V. Finally, Section VI concludes the paper and gives an overview about future work.

\section{RELATED WORK}

The simulation conducted in this paper is related to the work done in [7] where the building typology designed by the German Institute for Housing and Environment (IWU) ${ }^{3}$ was assigned to every building in the digital cadastre of Hamburg (ALKIS) in order to produce estimates for heat demand of individual buildings. The study conducted in [7] took into account the difficulties associated with a typologybased heat demand calculation approach like e.g. assumptions about building shell, incomplete data in digital cadastres, lack of data on renovation levels or lack of data on heating systems, and validated the results against a data-set of building energy certificates and the consumption values therein. Thereby, the authors found that while using the consumption-corrected heat demand values of the IWU-typology for individual buildings is rather difficult, using these values for groups of buildings, taking advantage of averaging-out-effects, does produces good results with average differences of $6 \%$ to $10 \%$ for different groups of buildings. This suggests that the typology-based heat demand calculation approach is plausible for large-scale studies or simulations like the one being conducted in this paper.

In [8] a procedure for creating a spatially referenced building stock with the population living therein in term of a

${ }^{3}$ http://www.iwu.de/1/home/, accessed September 11, 2017. synthetic city for Germany is presented. The authors used data from the German microcensus (2010) [9] which contains detailed sociodemographic characteristics of individuals and details information on the type of buildings in which these individual live. Based on this data a synthetic population and building stock was created. Records from the microcensus about the construction year and number of dwelling units of buildings were used to classify buildings by their estimated heat demand. Contrasting to the approach presented in this paper, the authors of [8] developed a micro-simulation model to estimate the heat demand of synthetic building stocks, while focusing on the dweller's influence on the heat demand instead of the dweller's renovation behavior like considered in this paper.

A different approach for the calculation of building heat energy demand based on 3D building models instead of a building typology is presented in [10]-[12]. There SimStadt [13], a workflow-driven urban energy simulation platform, is used to calculate the heat demand based on Open Geospatial Consortium (OGC) standard compliant CityGML [14] models. CityGML is an an open, multi-functional model that can be used for geospatial transactions, data storage and for the modeling of 3D buildings. Based on the surface of the 3D building models, information about their usage and climate data the heat energy demand of the examined building stock is calculated by SimStadt by also considering aspects like solar irradiance and shadowing. While this results in a sophisticated simulation model and a good estimation of the buildings heat energy demand, the approach is not suitable for the Hamburg 
scenario with more than a hundred thousand buildings due to its complexity and resulting scalability issues.

\section{Simulation ApproaCH}

The main goal of the simulation is to simulate the development of the building stock in the City of Hamburg from 2016 to 2050. Therefore, aspects like renovation, demolition, reconstruction as well as redensification have to be considered for residential and non-residential buildings. Arguably, different types of owners for various types of buildings will behave differently in terms of the aforementioned aspects. Thus, the simulation system is realized as a Multi-Agent based Simulation (MABS) [15], where the various owner types are mapped to different agents. The current version of the simulation system maps five particular types of homeowners of either detached or terraced houses. These five types were identified in a study on the renovation behavior of such house owners in Germany [5]. Therefore, in its current state the simulation system focuses on the renovation behavior of these special types of residential buildings. Future versions aim at supporting the renovation behavior of other types of residential buildings like apartment houses as well as nonresidential buildings like factories or administration buildings. Also aforementioned aspects like demolition, reconstruction and redensification are part of the objective.

The simulation is realized using Repast Simphony [6] an open source agent-based modelling environment that builds on the Repast 3 library [16]. One key feature of Repast Simphony with particular interest for this project is its GIS support. Repast Simphony provides geographic referencing through geography projections that correlate the agents to positions in space. An agent's representation in a geography projection corresponds to a specific geographical feature, such as points, lines or polygons. Repast Simphony uses GeoTools ${ }^{4}$, an open source Java GIS toolkit that is an OGC compliant library, to provide support for the feature types described above, along with additional GIS data types and functions. Repast Simphony's GIS capabilities also include support for Environmental Systems Research Institute (ESRI) Shapefiles [17] and a range of raster data files.

The geography projection is associated with a coordinate referencing system (CRS), which is based on the OGC standards and can be used to execute geographical queries on the topology of the agent features in the geography. Agents can query the geography to determine whether agent features overlap or are within a certain distance of, intersect with or border other agent features in the geography. Also of interest are Repast Simphony's 2D and 3D GIS visualization modules, that provide tools to view running models interactively.

Another agent-based simulation tool with GIS capabilities similar to Repast Simphony is GAMA [18]. The reason for using Repast Simphony as part of the GEWISS project is that it, unlike GAMA, allows to model agents in Java therefore supports Java's rich ecosystem. This makes Repast Simphony

${ }^{4}$ http://www.geotools.org/, accessed September 11, 2017 more suitable for the complex models and behaviors required in the GEWISS project. GAMA, on the other hand, is better suited for rapid prototyping because of its simple and easy to learn modeling language (GAML - GAMA Modeling Language [19]).

\section{Simulation System}

The developed simulation system will be described in more detail below. Thereby, the structure of the simulation, its individual phases and the underlying data sources will be presented. The first part of this section will describe the data sources and initialization phase, followed by a discussion about the buildings heat energy demand calculation within the simulation. Afterwards, the different building owner agents are going to be described. Finally, the result handling of the developed system is going to be presented. The architecture of the simulation system is shown in Figure 2 in order to illustrate the interaction of the different components and the execution order of the simulation.

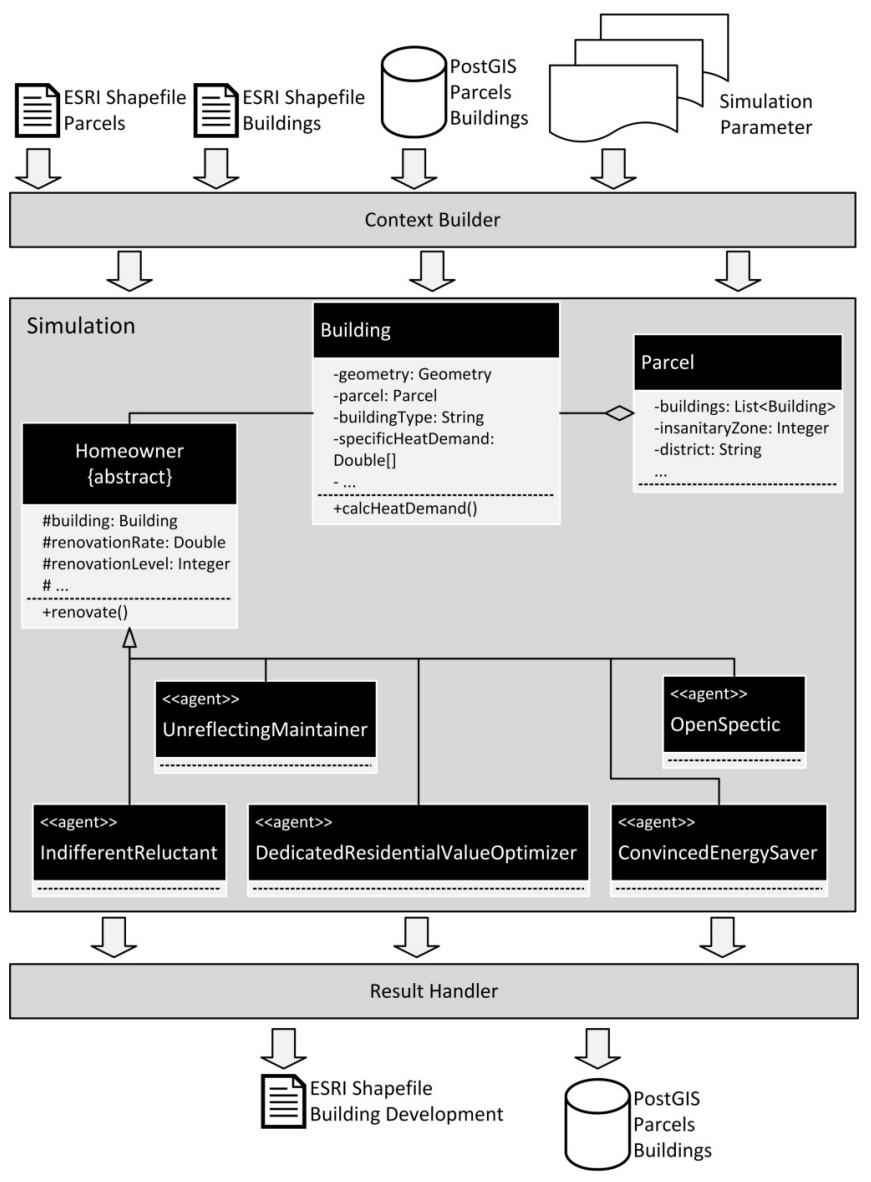

Fig. 2. Architecture of the developed simulation system.

\section{A. Initialization and Data Sources}

The Context Builder shown in Figure 2 processes various input parameters and data sources in order to create and configure the corresponding simulation objects. The buildings 
whose development (with regard to the renovation) should be simulated can be imported either from an ESRI Shapefile or a PostGIS ${ }^{5}$ database. The parcels on which the buildings were built can also be read from an ESRI Shapefile or a PostGIS database. On the basis of the parcels, it can be determined whether the building is located within a redevelopment zone and which development limits have to be adhered to in case of a refurbishment. The data sources of the buildings contain, among other things, information about the building's geometry, a reference to the parcel on which the building is located, the buildings type (detached or terraced house) and the specific heat energy demand.

The specific heat energy demand was determined in a study by the German Institute for Housing and Environment (IWU) for different types of buildings from different eras of construction [20]. Table I gives an overview about how the buildings are cataloged accordingly to the IWU study. Three different renovation levels have been taken into account, therefore a 3-tuple is obtained which includes the specific heat demand for the building type and era of construction in different renovation levels. Thereby, a renovation level of 0 means that the building has never been renovated since it was built, a renovation level of 1 means that the building has been renovated conventional accordingly to the German Energy Saving Ordinance (EnEV 2014 ${ }^{6}$ ) and a renovation level of 2 means that the building has been renovated according to the German Passive House Standard which is also defined in the EnEV 2014.

TABLE I

DIFFERENT TYPES OF BUILDINGS FROM DIFFERENT ERAS OF CONSTRUCTION CLASSIFIED ACCORDING TO THE IWU STUDY [20] (EXTRACT FROM THE ORIGINAL TABLE SHOWING ONLY DETACHED AND TERRACED HOUSES)

\begin{tabular}{|c|c|c|c|}
\hline \multicolumn{2}{|c|}{$\begin{array}{l}\text { Construction } \\
\text { Age Group }\end{array}$} & $\begin{array}{c}\text { Detached House } \\
\text { (DH) }\end{array}$ & $\begin{array}{c}\text { Terraced House } \\
\text { (TH) }\end{array}$ \\
\hline $\mathbf{A}$ & ... 1859 & DH_A & \\
\hline B & $1860 \ldots 1918$ & DH_B & TH_B \\
\hline $\mathbf{C}$ & $1919 \ldots 1948$ & DH_C & TH_C \\
\hline D & $1949 \ldots 1957$ & DH_D & TH_D \\
\hline $\mathbf{E}$ & $1958 \ldots 1968$ & DH_E & TH_E \\
\hline $\mathbf{F}$ & $1969 \ldots 1978$ & DH_F & TH_F \\
\hline $\mathbf{G}$ & $1979 \ldots 1983$ & DH_G & TH_G \\
\hline $\mathbf{H}$ & $1984 \ldots 1994$ & $\overline{\text { DH_H }}$ & TH_H \\
\hline I & $1995 \ldots 2001$ & DH_I & TH_I \\
\hline $\mathbf{J}$ & $2002 \ldots 2009$ & DH_L & TH_J \\
\hline $\mathbf{K}$ & $2010 \ldots 2015$ & DH_K & TH_K \\
\hline $\mathbf{L}$ & $2016 \ldots$ & DH_L & TH_L \\
\hline
\end{tabular}

All information about the buildings and the underlying parcels have been extracted from the Hamburg digital cadastre. It is part of a standardized cadastral system used throughout Germany to store information about the geometry of the objects as well as additional information like building use, construction year and construction type etc. The interpretation of these attributes and the logic used for assigning an IWU

\footnotetext{
${ }^{5}$ http://postgis.net/, accessed September 11, 2017

${ }^{6} \mathrm{http}: / /$ www.enev-online.com/enev_2014_volltext/, accessed September 11, 2017 (German source).
}

energetic building type to each building object based on its attributed is described in [7] (cf. Section II). As part of a joint work in the GEWISS project, the authors of [7] provided the data sources for the simulation so that each building is assigned with the according IWU energetic building type.

\section{B. Heat Demand Calculation}

When considering heat demand calculation it is crucial to differentiate between the terms demand, the calculated theoretical amount of energy needed, and consumption, the energy actually used by the building and its inhabitants, measured by devices. The consumption usually differs from the demand due to the building user's influence and seasonal climate conditions. Within the simulation, the heat energy demand is considered. The heat energy demand $\left(E_{H D}\right.$ in $\frac{k W h}{a}$ ) of a building is calculated by multiplying the specific thermal energy demand $\left(E_{S E D}\right.$ in $\left.\frac{k W h}{m^{2} * a}\right)$ for the building type according to the IWU typology $\left(I_{T}\right)$, taking into account the current renovation level $\left(R_{L}\right)$, with the gross floor area of the building $\left(A_{G F}\right.$ in $m^{2}$ ) and a so-called living space factor $\left(F_{L}\right)$. This factor indicates how much of the gross floor area is used for residential purposes which is the reference area for the specific heat demand (cf. [21, p. 18] and [20, p. 40]). The total gross floor area is computed based on the cadastre as footprint area multiplied by the number of full storeys (this is a simplification that could, to some extent, under- or overestimate the gross floor area but this is neglected for the purpose of the simulation). The specific building heat demand $E_{S E D}$ is taken as computed useful heat demand for space heating (without domestic hot water) in $k W h$ per square meter of the building's residential floor area. The climate zone is Hamburg. Additionally, a correction for typical consumptions levels is applied, see [20, p. 76-77]. This results in the following equation:

$$
E_{H D}=E_{S E D}\left[I_{T}, R_{L}\right] \cdot A_{G F} \cdot F_{L}
$$

\section{Home-owner Agents}

Currently, the simulation system focuses on simulating the renovation behavior of owners of detached and terraced houses. Thereby, it relies on the previously mentioned study about the renovation behavior of such owner types in Germany (cf. [5]). According to the study, there are five different types of home-owners with regards to their renovation behavior. These types and their ratio are shown in Table II. During the initialization phase the Context Builder creates a home-owner agent for each building read either from the ESRI shapefile or the PostGIS database and randomly maps the agent to one of the five renovator types with a probability matching the ratio shown in Table II.

Figure 2 shows that for each of these five types a specific agent class is implemented that extends the abstract Homeowner super-class. Thereby, the sub classes implement the super class by specifying the renovation behavior of the owner type. In fact, this is done by providing a general renovation rate for the owner type and the level of the renovation (cf. Section IV-A). The Homeowner super-class 
TABLE II

RATIO AND RENOVATION LEVEL OF DIFFERENT HOME-OWNER TYPES (DETACHED AND TERRACED HOUSES) ACCORDING TO [5].

\begin{tabular}{|l|l|l|}
\hline \multicolumn{1}{|c|}{ Type } & Ratio & Renovation Level \\
\hline Unreflecting Maintainer & $12 \%$ & 1 \\
\hline Indifferent Reluctant & $14 \%$ & 1 \\
\hline Dedicated Residental Value Optimizer & $20 \%$ & 1 \\
\hline Convinced Energy Saver & $25 \%$ & 2 \\
\hline Open Sceptic & $29 \%$ & 2 \\
\hline
\end{tabular}

provides common behavior that determines whether or not a home-owner agent renovates its building in the current simulation step. The simulation is carried out in discrete steps, where each simulation step corresponds to one year. Thus, a simulation of the development of the building stock from 2016 to 2050 corresponds to 34 simulation steps. The common agent behavior defined by the Homeowner super-class consists out of three steps:

1) Checking the renovation condition.

2) If the renovation condition is met, calculating the renovation probability.

3) Performing the actual renovation depending on the probability.

This behaviour is described in more detail below.

1) Renovation Condition: For an owner agent to renovate its building, the following two renovation conditions must be met:

1)

$$
R_{L}=0,
$$

with $R_{L}$ as the renovation level of the building. A renovation level of 0 means the building has never been renovated before.

2) The building has not been renovated within the minimal renovation interval $\left(R_{I}\right)$ which is a configurable parameter of the simulation:

$$
R_{Y} \leq\left(C_{Y}-R_{I}\right)
$$

where $R_{Y}$ indicates the last year of renovation for the building and $C_{Y}$ is current year.

2) Renovation Probability: The renovation probability $R_{P}$ expresses the probability that a home-owner agent will renovate its building within the current simulation step. The probability is composed of the global renovation rate of the owner type $\left(R_{T}\right)$, a redevelopment area multiplier $\left(M_{R a}\right)$ if the building is located in a redevelopment area and the so called neighborhood multiplier $\left(M_{N}\right)$. The redevelopment area multiplier $\left(M_{R a}\right)$ is determined by increasing the redevelopment area level by 1 . Accordingly, a value of 1 is obtained for a non-existent redevelopment area. In the case of an area with maximum redevelopment promotion, a multiplier of 4 is obtained. The neighborhood multiplier as well as the according neighborhood radius $\left(N_{R}\right)$ are configurable parameters of the simulation. The neighborhood radius $N_{R}$ narrows the area that is considered as the neighborhood of the building. This results in the following renovation probability:

$$
R_{P}=R_{T} \cdot M_{R a} \cdot M_{N}
$$

with

$$
M_{N}= \begin{cases}1 & \text { if no renovated buildings within } N_{R} \\ \gamma & \text { min } 1 \text { renovated building within } N_{R}\end{cases}
$$

where $\gamma$ is a configurable parameter of the simulation.

Figure 3 shows an extract from the map of Hamburg, where redevelopment areas have been defined by the city in order to stimulate the renovation of buildings in the district Billstedt. In the case of the simulation, buildings within one of these redevelopment areas have a higher probability to be renovated than buildings outside these areas (compare equation above).

3) Renovation Behavior: The renovation behavior of the building owner agents is determined by their type. As a simplification for the sake of simulation, the renovation behavior is realized by setting the owned building to the according renovation level with the renovation probability calculated in the previous step. Thereby, home-owner agents of the type of Unreflecting Maintainer, Indifferent Reluctant and Dedicated Residential Value Optimizer renovate their building accordingly to the German Energy Saving Ordinance (renovation level 1). Home-owner agents of the type of Convinced Energy Saver and Open Sceptic renovate their building according to the German Passive House Standard (renovation level 2). In summary, the ratio and the renovation level of the different owner types are shown in Table II. The original study [5] distinguishes between renovation as a simple act of maintenance (e.g. repainting facades and fixing damages) and energetic retrofitting (e.g. adding insulation materials or changing heat supply systems), which different owner types are more or less likely to undertake. For the simulation however, we only consider renovations in terms of a energetic retrofitting with two levels of quality.

\section{Result Handling}

Result handling is done by the Result Handler a specialized agent responsible for collecting result data in each discrete simulation step by observing the set of buildings. In each step, it stores information about the renovation level and the dependent heat demand of the buildings. These result series are stored in the PostGIS database, so they can be linked to be building tables where the corresponding geometries are stored in order to visualize the results in form of a GIS. In addition, the Result Handler agent creates an ESRI Shapefile that stores the renovation level and heat demand for each building for each year, making it possible to directly load the results to a GIS tool such as $Q G I S^{7}$ where they can be processed and visualized further (cf. Figure 2).

\footnotetext{
${ }^{7}$ Open Source Geographic Information System, https://www.qgis.org, accessed September 11, 2017
} 


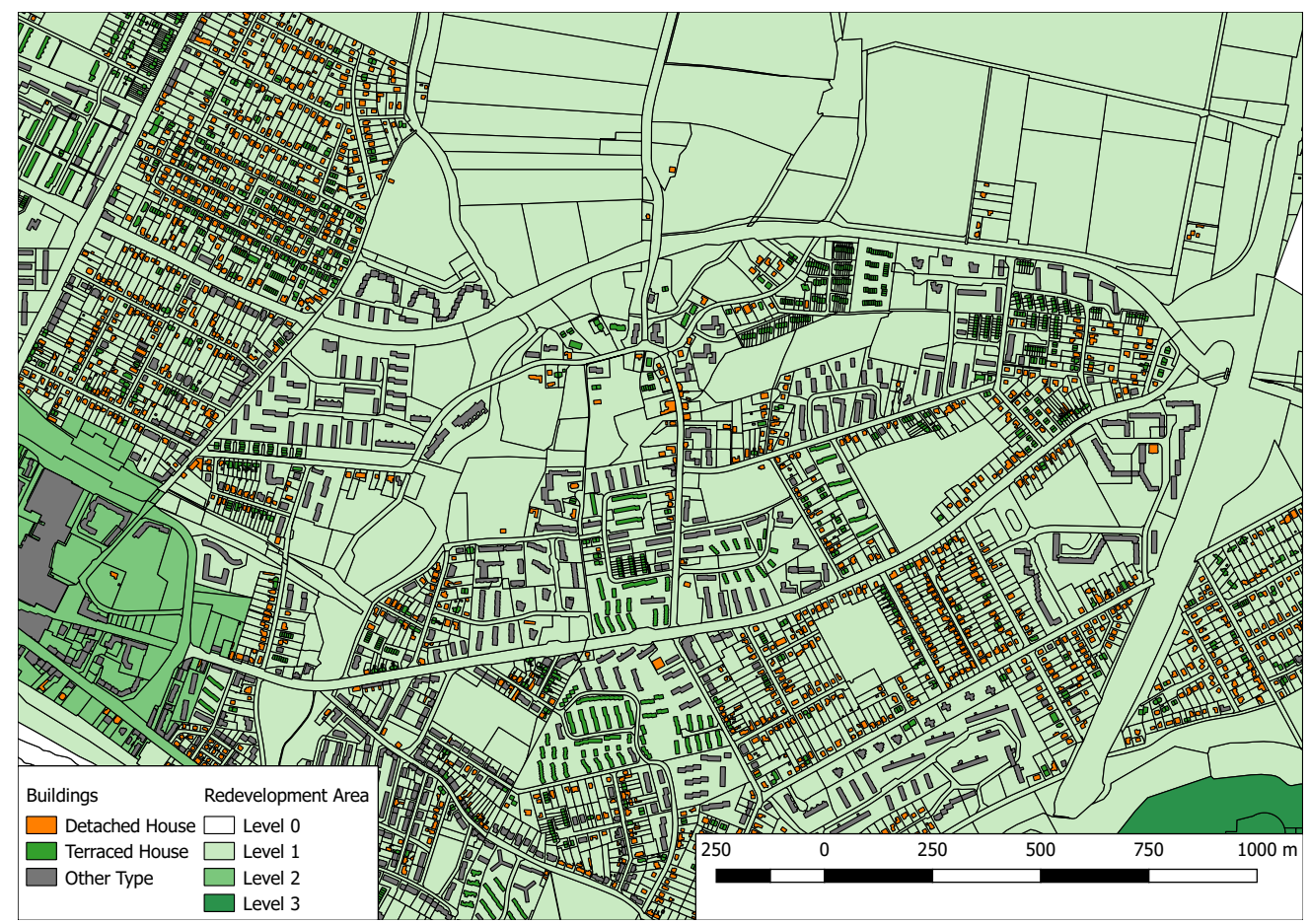

Fig. 3. Map extract from Hamburg showing detached and terraced houses in different levels of redevelopment areas in the district Billstedt.

\section{RESUlts}

This section will describe first results of the simulation system with regard to the advancement of building renovation in Hamburg from 2016 to 2050 and depending on that, how the simulated renovation behavior affects the overall heat demand of residential buildings (detached and terraced houses) in the city. Table III lists the simulation parameters for a default reference scenario. It shows the global renovation rates of the five renovator types according to [5], which were allocated to the house owners according to the distribution shown in Table II. The values for the renovation rates shown in the table are estimated from the description in [5]. The minimal renovation interval states the minimum age of a building so that an owner would consider renovating it, while the vicinity range narrows the area that is defined as the neighborhood of the owner's building and the vicinity factor states the value the renovation rate is multiplied by, if a building in the neighborhood has already been renovated (cf. Section IV-C).

All detached and terraced houses in Hamburg, as identified by [7] were considered in the simulation. Thus, a home-owner agent was created for each building and configured as one of the five renovator types identified in [5] according to the ratio depicted in Table II. This resulted in a total of 151.636 buildings ${ }^{8}$ respectively agents being simulated. The results of the above-mentioned simulation parameter configuration is depicted in Figure 4. There the $\mathrm{x}$-axis depicts the simulated year, the primary $y$-axis on the left shows the overall heat demand in $\frac{G W h}{a}$ and the secondary y-axis on the right gives information

${ }^{8}$ This is more than half of all residential buildings in Hamburg.
TABLE III

SiMUlation PARAMETERS FOR THE default SCENARIO.

\begin{tabular}{|l|l|l|}
\hline Parameter & Value \\
\hline Renovation Rates & & \\
\hline & Unreflecting Maintainer & $3 \%$ \\
\hline & Indifferent Reluctant & $1 \%$ \\
\hline & Dedicated Residential Value Optimizer & $5 \%$ \\
\hline & Convinced Energy Saver & $5 \%$ \\
\hline \multicolumn{2}{|l}{ Minimal renovation Interval (year) } & $2.5 \%$ \\
\hline Vicinity & Open Sceptic & 10 \\
\hline \multicolumn{2}{l}{$(\mathrm{m})$} & 100 \\
\hline & Range & 2 \\
\hline
\end{tabular}

about the number of buildings in a specific renovation level. The figure shows two aspects, first the development of the overall heat demand (sum of the heat demand of all 151.636 buildings) is depicted by the orange bars, second the progression of the renovation level. Thereby, the black curve shows the number of buildings that have not been renovated yet (renovation level 0 ), the blue curve shows the number of buildings that have been renovated according to the German Energy Saving Ordinance (renovation level 1) either by an Unreflecting Maintainer, an Indifferent Reluctant or a Dedicated Residential Value Optimizer. Finally, the green curve depicts the number of buildings that have been renovated according to the German Passive House Standard either by a Convinced Energy Saver or an Open Sceptic. Figure 4 shows how the overall heat demand of the considered buildings can be reduced by a third from about $1500 \frac{G W h}{a}$ in 2016 to about $1000 \frac{G W h}{a}$ in 2050 if the buildings would be renovated with the assumed rates. 


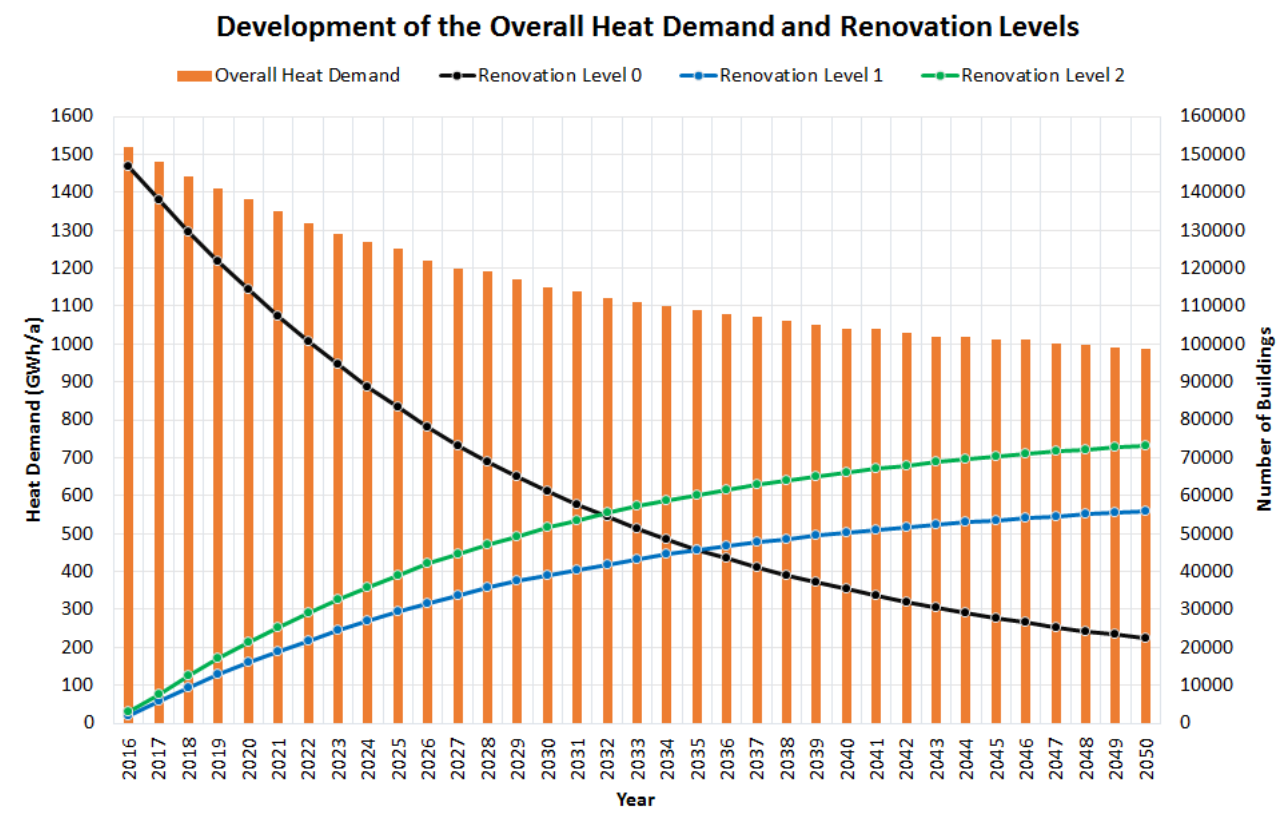

Fig. 4. Simulation results of the scenario depicted in Table III. The x-axis shows the simulated year, the primary y-axis on the left the overall heat demand in $\frac{G W h}{a}$ and the secondary y-axis on the right the number of detached and terraced houses in a specific renovation level.

The figure also shows that in order to achieve such a reduction of heat energy demand the number of non-renovated buildings has to be reduced significantly from around 150.000 to around 20.000 .

The Hamburg digital cadastre does not contain information about construction materials or renovation status. Hence, all buildings were assumed to be in their initial (baseline) condition without any refurbishments. Although most buildings do not include the original windows or heating system from when they were constructed, but more recent ones. Nevertheless their overall efficiency is a lot lower than the EnEV 2014 or German Passive House standards. Since some buildings with better than baseline renovation level are most likely present, the initial heat demand in the simulation might be higher than the demand of the actual building stock. Different qualities in regard to the buildings' conditions and thermal insulation are mapped by the construction year of the building and the linked IWU-type (cf. Table I).

Figure 5 shows a cartographic representation of the calculated heat demand in 2050 as it would be provided by a GIS. The gray buildings in the figure show either non-residential buildings or residential buildings which are neither detached nor terraced houses, so that no heat demand was calculated in the simulation for these buildings. The calculated heat demand is depicted as $\frac{M W h}{a}$. This means that the absolute heat demand of the buildings is represented and not the heat demand per square meter. Larger buildings therefore have a higher heat demand than small buildings. In this representation, the heat demand does not allow any conclusions on the state of the thermal insulation of the building. In contrast, Figure 6 shows the renovation level of the buildings in 2050. Thereby, it becomes clear that only a few buildings remain in a nonrenovated state (see also Figure 4).

\section{CONCLUSiOn AND Future WORK}

In this paper we presented an agent-based simulation system that aims at simulating the building stock development in the city of Hamburg. In its current version it focuses on simulating the renovation behavior of detached and terraced house owners. Thereby, it implements different behaviors for the five renovator types identified in a study about the renovation behavior of detached and terraced house owners in Germany [5] by mapping these types to different agents and assigning them as home-owners to the building stock. The resulting simulation system uses data about the buildings and parcels from Hamburg's digital cadastre and uses the approach presented in [7] to assign an energetic building type according to the IWU-typology about different buildings types in Germany [20]. The IWU building typology also contains information about the specific thermal energy consumption of the different building types for different renovation levels. This is used to calculate the heat energy demand of the buildings. This paper leaves new construction, redensification, or change in usage/mix-usage or rebound effects out of scope. This would be required for a more realistic simulation of the heat energy demand of residential buildings in the city of Hamburg. Furthermore this work assumes fixed fractions of owner-types (cf. Table II), a socioeconomic approach could use adjusted fractions on the basis of the German microcensus [9].

The simulation system simulates in discrete steps the development of the renovation levels of the buildings from 2016 to 2050 (one step equals one year). Thereby, it determines the 


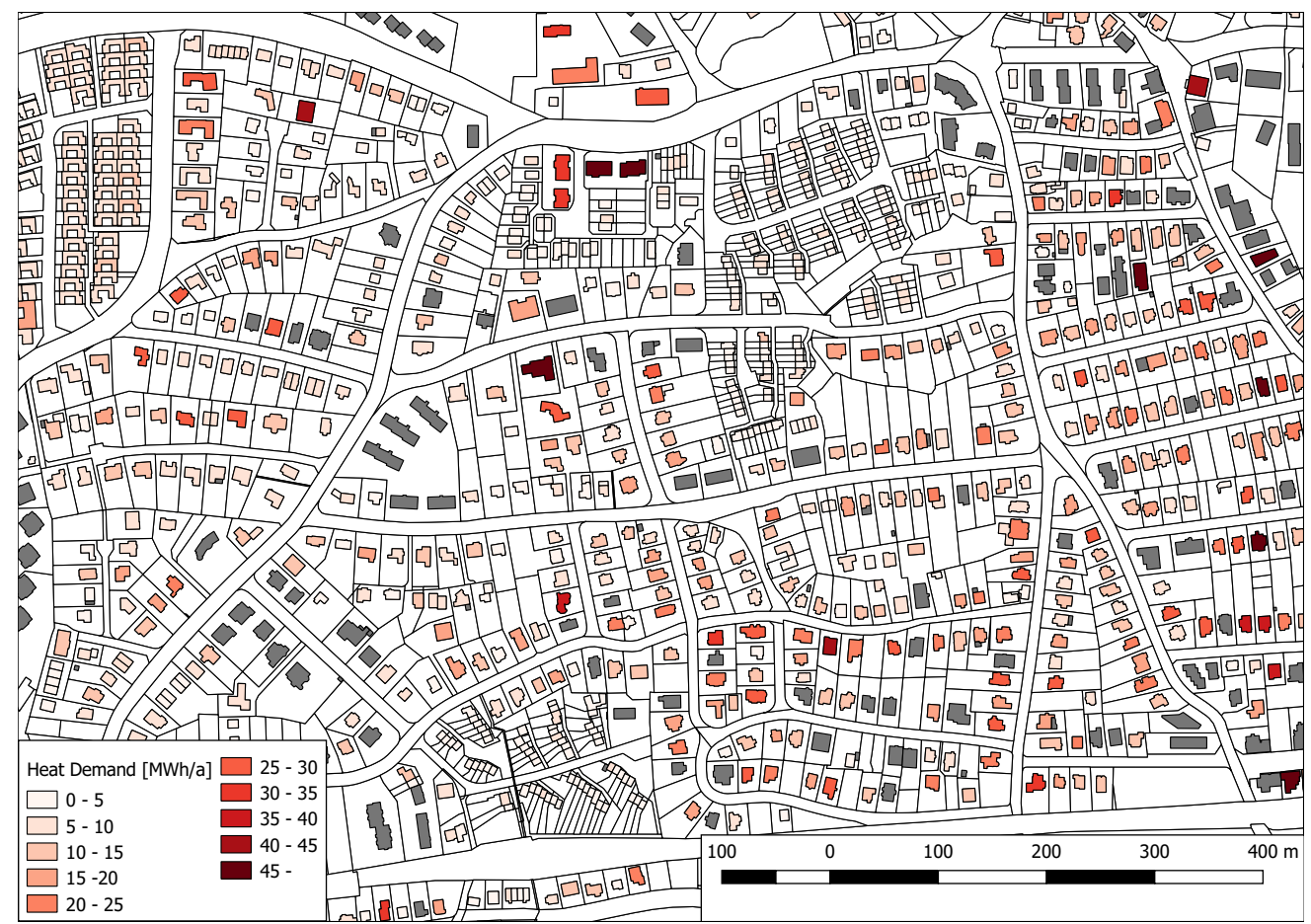

Fig. 5. Cartographic representation of the calculated heat demand for detached and terraced houses according to the IWU-typology in the district Othmarschen for the year 2050 based on the simulation scenario depict in Table III.

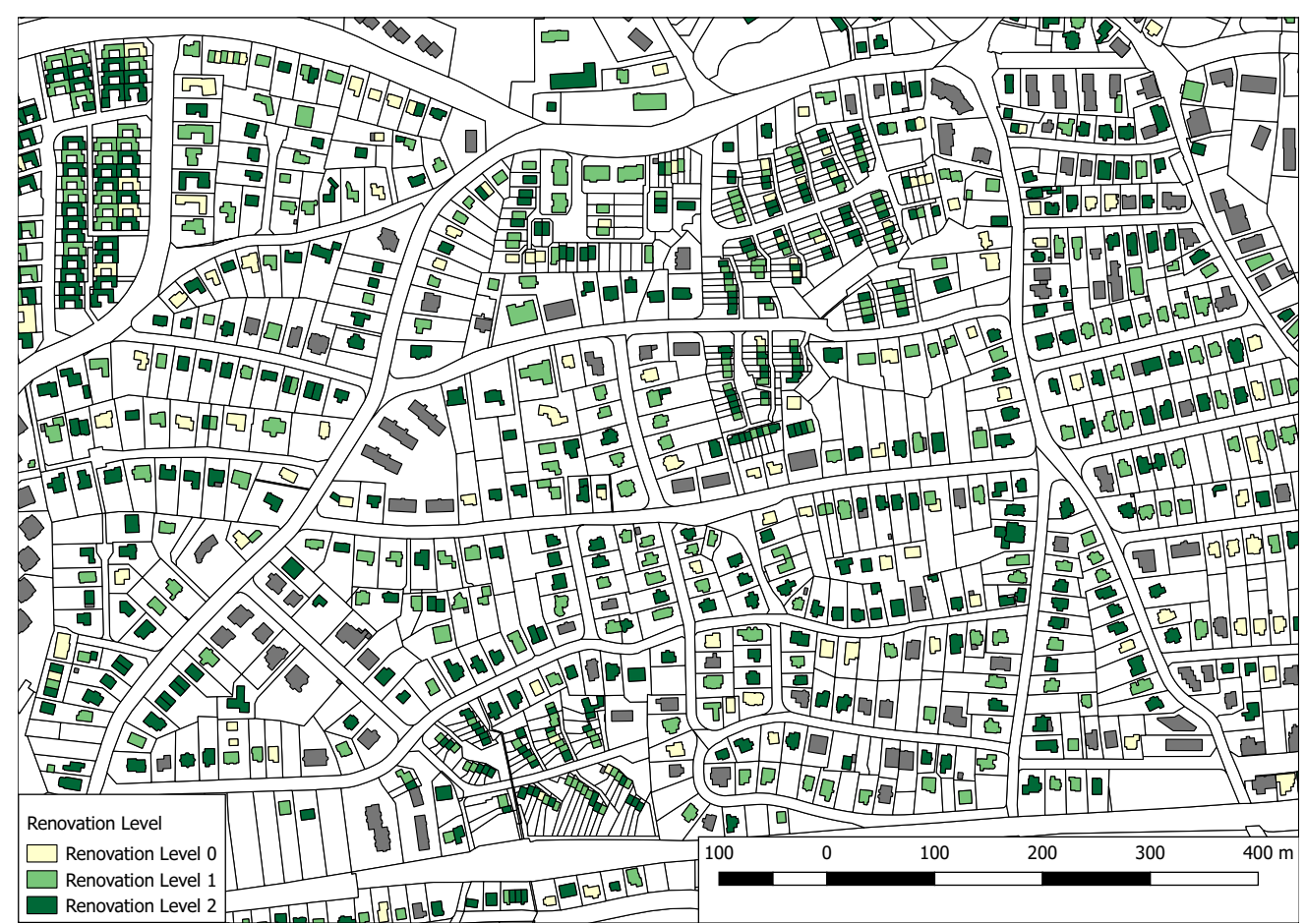

Fig. 6. Cartographic representation of the renovation level for detached and terraced houses in the district Othmarschen for the year 2050 based on the simulation scenario depict in Table III. 
renovation probability for each building in each year by incorporating factors like the building's age, possible redevelopment zones, the renovation willingness of the owner type according to the study from [5] and possible neighborhood effects, where an owner is more willing to renovate his building, if he witnesses a renovation in his neighborhood. Based on this, first simulation results showed that the heat demand for detached and terraced houses in Hamburg can be significantly reduced if the owners behave according to the assumed simulation parameters. However, these simulation parameters still harbor a series of uncertainties and assumptions which have a significant influence on the renovation behavior and thus the resulting development of the heat demand. Therefore, we want to provide an exploratory tool with the simulation system to be used by interested stakeholders to investigate the influence of different measures, parameters and assumptions on the renovation behavior and thus the development of the heat demand.

Future work will focus on two different aspects. The first aspect considers the improvement of the simulation model. Here it is planned to simulate the renovation behavior of other types of building owners apart from the reviewed owners of detached and terraced houses. This includes different owner types for apartment houses, like residential building cooperatives that own multiple buildings and follow a non-profit interest, housing societies also owning multiple buildings but focusing on commercial profit or individual persons owning a block of flats also with a commercial interest.

The second aspect considers the interoperability of the proposed simulation system as well as the provision of a web visualization and user interface. Here it is envisioned to encapsulate the simulation system as a web-service following the approach presented in [22]. This is to enable the simulation system to be called from other systems in a standardized way in order to possibly be integrated in the context of a co-simulation system. Furthermore, it is planned to provide the simulation system as a data-adaptive simulation service following the concept described in [23]. Data-adaptivity in this context means that the system is adaptive with regards to its data, resulting in a data/knowledge space that is filled on demand. If the required data for a simulation request already exists it is returned directly, if not the required simulation is performed and the data/knowledge space is enriched with this information. Especially in the context of an exploratory tool, this approach allows to build up an increasingly extensive knowledge space, which allows repetitive queries to be answered very quickly, which then allows to provide an interactive web-based user interface where interested stakeholders can explore different simulation scenarios. For first-time simulation queries with no preexisting results, it is planned to develop an asynchronous solution based on MQTT [24], [25], which asynchronously sends intermediate simulation results to the client so that it can visualize first partial results and thus be more responsive.

\section{ACKNOWLEDGEMENT}

This paper was developed within the GEWISS project, which is funded by the German Federal Ministry for Economic Affairs and Energy (BMWi) as part of the EnEff:Stadt program.

\section{REFERENCES}

[1] T. Klaus, C. Vollmer, K. Weber, H. Lehmann, and K. Müschen, "Energy target 2050: 100\% renewable electricity supply," Federal Environment Agency Germany, Tech. Rep., 2010.

[2] S. Musa, "Smart cities - a roadmap for development," Journal of Telecommunications System and Management, vol. 5, no. 144, 2016. doi: 10.4172/2167-0919.1000144. [Online]. Available: https://www.omicsgroup.org/journals/ smart-cities--a-roadmap-for-development-2167-0919-1000144.pdf

[3] S. Ackmann, I. Dochev, D. Hering, M. Gottschick, L. Knopp, S. Ochse, I. Peters, T. Preisler, W. Renz, and H. Seller, "GEWISS - Geographisches WärmeInformations- und SimulationsSystem," in Kongress 2017: EnergieEffizienzBauen, 2017.

[4] T. Preisler, T. Dethlefs, and W. Renz, "Simulation as a service: A design approach for large-scale energy network simulations," in 2015 Federated Conference on Computer Science and Information Systems (FedCSIS), Sept 2015. doi: 10.15439/2015F116 pp. 1765-1772.

[5] I. Stieß, V. van der Land, B. Birzle-Harder, and J. Deffner, "Handlungsmotive, -hemmnisse und Zielgruppen für eine energetische Gebäudesanierung - Ergebnisse einer standardisierten Befragung von Eigenheimsanierern," Energieeffiziente Sanierung von Eigenheimen, resreport, 2010

[6] M. J. North, N. T. Collier, J. Ozik, E. R. Tatara, C. M. Macal, M. Bragen, and P. Sydelko, "Complex adaptive systems modeling with repast simphony," Complex Adaptive Systems Modeling, vol. 1, no. 1, p. 3, 2013. doi: 10.1186/2194-3206-1-3. [Online]. Available: http://dx.doi.org/10.1186/2194-3206-1-3

[7] I. Dochev, E. Muñoz, H. Seller, and I. Peters, "Assigning iwu building types to buildings in the hamburg alkis," 2017.

[8] E. Muñoz H., I. Dochev, H. Seller, and I. Peters, "Constructing a synthetic city for estimating spatially disaggregated heat demand," International Journal of Microsimulation, vol. 9, no. 3, pp. 66-88, 2016 [Online]. Available: http://EconPapers.repec.org/RePEc:ijm:journl:v:9:y: 2016:i:3:p:66-88

[9] N. Schwarz, "The german microcensus," Schmollers Jahrbuch, no. 121, pp. 649-654, 2001.

[10] R. Nouvel, C. Schulte, U. Eicker, D. Pietruschka, and V. Coors, "Citygml-based 3d city model for energy diagnostics and urban energy policy support," in Proceedings of the 13th conference of international Building Performance Simulation Association, 2013, pp. 218-25.

[11] R. Nouvel, M. Zirak, H. Dastageeri, V. Coors, and U. Eicker, "Urban energy analysis based on 3d city model for national scale applications," in Fifth German-Austrian IPBSA Conference, 2014.

[12] P. Wate and V. Coors, " $3 \mathrm{~d}$ data models for urban energy simulation," Energy Procedia, vol. 78, pp. 3372 - 3377, 2015. doi: http://dx.doi.org/10.1016/j.egypro.2015.11.753. [Online]. Available: http://www.sciencedirect.com/science/article/pii/S1876610215024856

[13] R. Nouvel, K. H. Brassel, M. Bruse, E. Duminil, V. Coors, U. Eicker, and D. Robinson, "Simstadt, a new workflow-driven urban energy simulation platform for citygml city models," in Proceedings of the CISBAT International Conference 2015, 2015.

[14] Open Geospatial Consortium, "Ogc city geography markup language (citygml) encoding standard," 2012. [Online]. Available: https: //portal.opengeospatial.org/files/?artifact_id=47842

[15] P. Davidsson, "Multi agent based simulation: Beyond social simulation," in Proceedings of the Second International Workshop on Multi-agent Based Simulation, ser. MABS 2000. Secaucus, NJ, USA: SpringerVerlag New York, Inc., 2001. ISBN 3-540-41522 pp. 97-107. [Online] Available: http://dl.acm.org/citation.cfm?id=369837.369846

[16] M. J. North, N. T. Collier, and J. R. Vos, "Experiences creating three implementations of the repast agent modeling toolkit," ACM Trans. Model. Comput. Simul., vol. 16, no. 1, pp. 1-25, Jan. 2006. doi: 10.1145/1122012.1122013. [Online]. Available: http://doi.acm.org/10. $1145 / 1122012.1122013$ 
[17] Environmental Systems Research Institute, "White paper: Esri shapefile technical description:," Environmental Systems Research Institute, Inc. techreport, 1998. [Online]. Available: https://www.esri.com/library/ whitepapers/pdfs/shapefile.pdf

[18] A. Grignard, P. Taillandier, B. Gaudou, D. A. Vo, N. Q. Huynh, and A. Drogoul, GAMA 1.6: Advancing the Art of Complex AgentBased Modeling and Simulation. Berlin, Heidelberg: Springer Berlin Heidelberg, 2013, pp. 117-131. ISBN 978-3-642-44927-7. [Online]. Available: http://dx.doi.org/10.1007/978-3-642-44927-7_9

[19] D.-A. Vo, A. Drogoul, J.-D. Zucker, and T.-V. Ho, A Modelling Language to Represent and Specify Emerging Structures in AgentBased Model. Berlin, Heidelberg: Springer Berlin Heidelberg, 2012, pp. 212-227. ISBN 978-3-642-25920-3. [Online]. Available: http://dx.doi.org/10.1007/978-3-642-25920-3_15

[20] T. Loga, B. Stein, N. Diefenbach, and R. Born, "Deutsche Wohngebäudetypologie - Beispielhafte Maßnahmen zur Verbesserung der Energieeffizienz von typischen Wohngebäuden," IWU Institut Wohnen und Umwelt, Tech. Rep., 2015. [Online]. Available: http://www.building-typology.eu/downloads/public/docs/brochure/ DE_TABULA_TypologyBrochure_IWU.pdf
[21] "Richtlinienausschuss VDI 3807 Verbrauchskennwerte für Gebäude," Verein Deutscher Ingenieure, Düsseldorf, DE, Standard, 1994.

[22] T. Preisler, G. Balthasar, T. Dethlefs, and W. Renz, "Scalable integration of 4gl-models and algorithms for massive smart grid simulations and applications," in 28th International Conference on Informatics for Environmental Protection: ICT for Energy Effieciency, EnviroInfo 2014, Oldenburg, Germany, September 10-12, 2014., J. M. Gómez, M. Sonnenschein, U. Vogel, A. Winter, B. Rapp, and N. Giesen, Eds BIS-Verlag, 2014. ISBN 978-3-8142-2317-9 pp. 341-348. [Online]. Available: http://www.enviroinfo2014.org/

[23] T. Preisler, T. Dethlefs, and W. Renz, "Data-adaptive simulation: Cooperativeness of users in bike-sharing systems," in Proceedings of the Hamburg International Conference of Logistics, W. Kersten, T. Blecker, and C. M. Ringle, Eds., vol. 20. epubli GmbH, 2015.

[24] U. Hunkeler, H. L. Truong, and A. Stanford-Clark, "Mqtt-s - a publish/subscribe protocol for wireless sensor networks," in Communication Systems Software and Middleware and Workshops, 2008. COMSWARE 2008. 3rd International Conference on, Jan 2008. doi: 10.1109/COMSWA.2008.4554519 pp. 791-798.

[25] A. Banks and R. Gupta, "Mqtt version 3.1. 1," OASIS standard, 2014. 